\title{
INCONTINENTIA PIGMENTI MIMICKING A HERPES SIMPLEX VIRUS INFECTION IN THE NEWBORN
}

\author{
Allappa Mallappa Koppad ${ }^{1}$, Rohit Ramavtar Agarwal ${ }^{2}$
}

1 Professor, Department of Paediatrics, Krishna Institute of Medical Sciences, Deemed University, Karad. ${ }^{2}$ Resident, Department of Paediatrics, Krishna Institute of Medical Sciences, Deemed University, Karad.

ABSTRACT

\section{BACKGROUND}

Incontinentia pigmenti is a rare, X-linked dominant multisystem genodermatosis that presents at or soon after birth with characteristic cutaneous signs. The main features occur in the skin where a blistering rash occurs in the newborn period, followed by the blisters becoming raised like warts. After the skin, the central nervous system is the next most affected system.

\section{CASE REPORT}

We report a newborn female baby who was born with vesicular eruptions, initially thought to have congenital herpes simplex virus infection.

\section{CONCLUSION}

This case report emphasises that Incontinentia pigmenti should be included in the differential diagnosis of cutaneous blistering lesions and central nervous system involvement in neonates.

\section{KEYWORDS}

Incontinentia Pigmenti, Herpes Simplex Virus, Newborn.

HOW TO CITE THIS ARTICLE: Koppad AM, Agarwal RR. Incontinentia pigmenti mimicking a herpes simplex virus infection in the newborn. J. Evolution Med. Dent. Sci. 2016;5(102):7506-7508, DOI: 10.14260/jemds/2016/1699

\section{BACKGROUND}

Incontinentia pigmenti (IP), also known as Bloch-Sulzberger syndrome, is a rare, $\mathrm{X}$-linked, dominant condition characterised by developmental abnormalities of the skin, hair, teeth, and central nervous system (CNS). After the skin, the CNS is the next most affected system. [1] The cause of IP has recently been traced to a defective gene on the $\mathrm{X}$ chromosome called NEMO/IKK-gamma, which is located on chromosome Xq28. The NEMO/IKK-gamma gene produces a protein that is essential for cells in the signalling pathways of apoptosis and inflammatory responses.[2]

The main features of IP are found in the skin where a blistering rash occurs in the newborn period. In this report, we describe a newborn that had vesicular eruptions and seizures and was initially thought to have congenital herpes simplex virus (HSV) infection.
Financial or Other, Competing Interest: None

Submission 15-11-2016, Peer Review 07-12-2016,

Acceptance 15-12-2016, Published 22-12-2016.

Corresponding Author:

Dr. Rohit Ramavtar Agarwal,

Ward 14,

Krishna Institute of Medical Sciences

Deemed University,

Karad-415110, Satara

Maharashtra.

E-mail: rohitagarwal3369@gmail.com

DOI: $10.14260 /$ jemds/2016/1699

\section{Case Report}

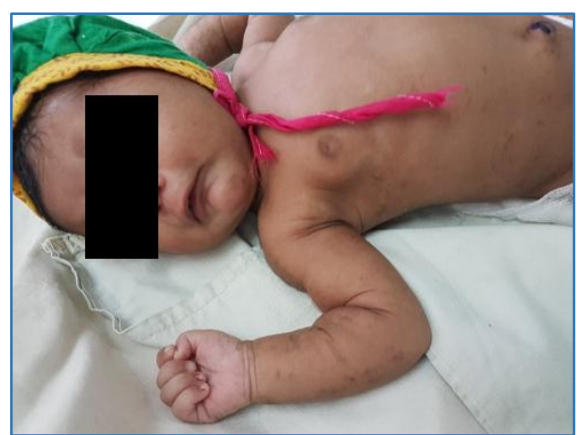

Figure 1 A

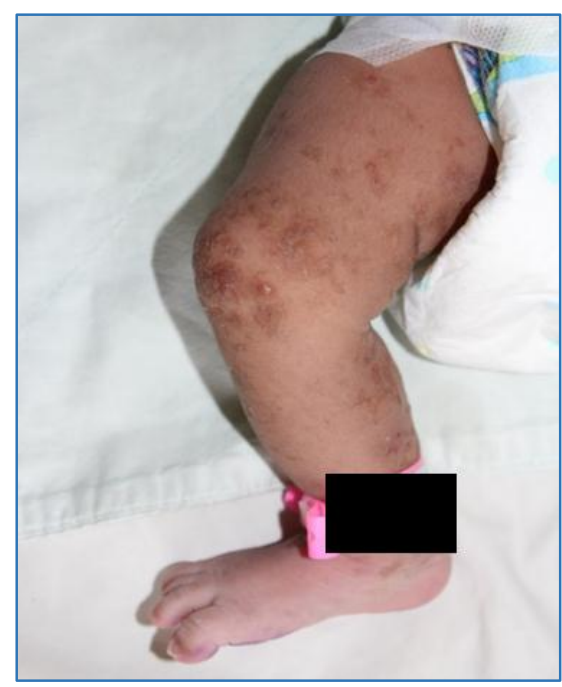

Figure 1 B

Figure 1 A, B. Erythematous vesicles on a red base arranged in linear groups on the upper and lower limbs 
A female newborn was referred to our neonatal unit because of vesicular skin lesions on the upper and lower extremities. She was born at full term to a 25 -year-old primigravida mother by caesarean section in Krishna Hospital. Maternal history was not significant. Prenatal and natal history was unremarkable.

On admission to our neonatal unit, physical examination revealed a well-appearing, afebrile infant, with erythematous vesicles on a red base arranged in linear groups on the upper and lower limbs. Septic screening was found to be negative; local therapy with antibiotics was initiated. On the $5^{\text {th }}$ day, baby developed a seizure, which was characterised by a staring gaze and motor manifestations such as diffuse extension with hypertonia of the upper limbs. These episodes occurred two times over $1 \mathrm{hr}$., and each lasted approximately 30-40 sec.

Results of laboratory studies included a haemoglobin concentration of $16.9 \mathrm{~g} / \mathrm{L}$, haematocrit value of $50.5 \%$, white blood cell count of $20,880 / \mathrm{mm}^{3}$ with $81 \%$ neutrophils, $19 \%$ lymphocytes, $2 \%$ band forms, and the platelet count was 2.85 lakhs $/ \mathrm{mm}^{3}$. Serum biochemical values, including C-reactive protein, electrolytes were in the normal range.

Magnetic resonance imaging of the brain showed multiple areas with cytotoxic oedema in the bilateral frontal, occipital, temporal region ( $\mathrm{L}>\mathrm{R}$ ), midbrain, pons, genu \& splenium of corpus callosum. A lumbar puncture revealed $0.5 \mathrm{~mL}$ of clear, colourless fluid without any cells, Glucose- $80 \mathrm{mg} / \mathrm{dL}$, and Protein-79 mg/dL. No bacterial growth seen in the blood and cerebrospinal fluid culture.

HSV-1 immunoglobulin (Ig) G was positive, and HSV-1 IgM, HSV-2 IgG, and IgM were negative in the serum. The polymerase chain reaction assays for the HSV-1 and HSV-2 deoxyribonucleic acid in the serum and cerebrospinal fluid were not done. The infant was empirically given intravenous acyclovir for suspected congenital herpes simplex infection and phenobarbital for the management of seizures. No other abnormal findings were noted.

Culture of vesicle fluid was negative for bacteria. The ophthalmologic examination was normal. Electroencephalography shows normal study. Magnetic resonance imaging (MRI) of the brain demonstrated - in figures below.

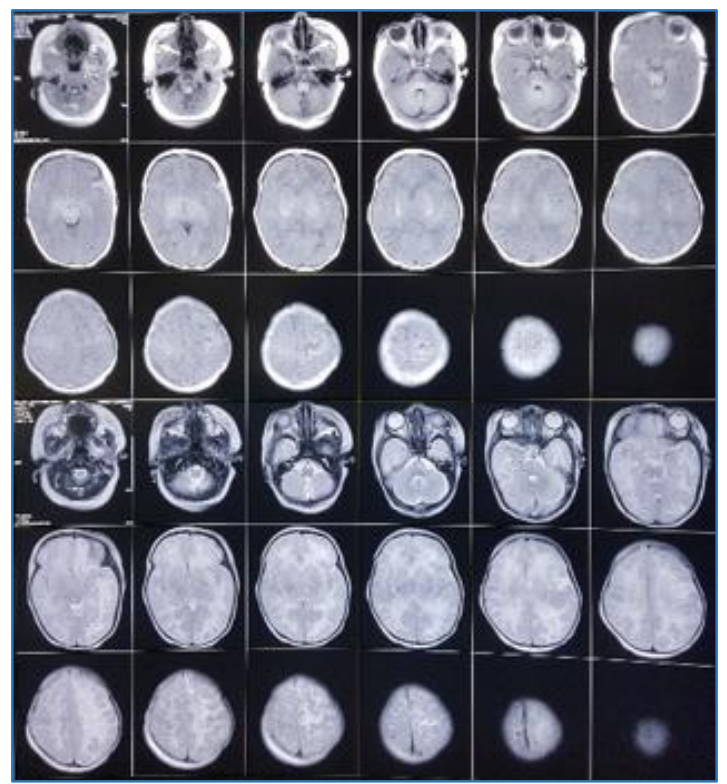

Figure $2 \mathrm{~A}$

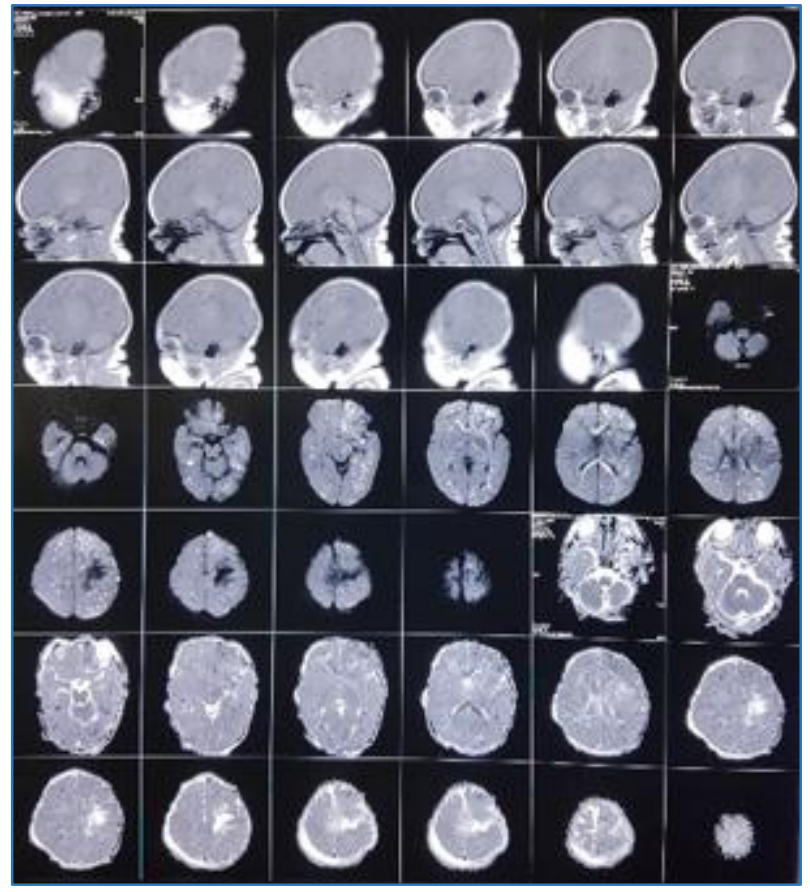

Figure 2 B

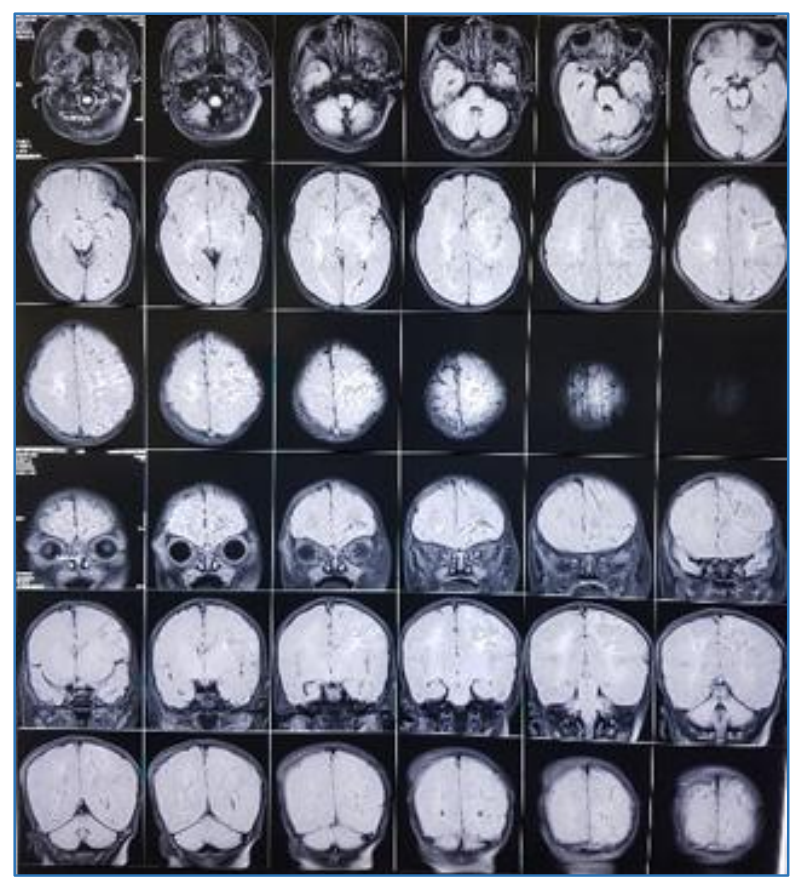

Figure 2 C

Figure 2 a, b, c- Bilateral nearly symmetric white matter with signal abnormalities. Frontal, Temporal, Parietal \& Occipital region involving Genu \& rostrum of Corpus callosum with Ant. \& Post. Limbs of internal capsule. These lesions show diffuse restriction and have low value on ADC mapping. These lesions appear hypointense on $\mathrm{T}_{1}$, while hyperintense on flare and $\mathrm{T}_{2}$. There is distinct high parietal, central semi-oval lesion - shows GRE blooming.

As skin biopsy specimen showed eosinophilic spongiosis and dyskeratotic epithelial cells adjacent to spongiotic microvesicles, it was realised that this is consistent with a diagnosis of IP, and the treatment with acyclovir and antibiotics was discontinued. 
The gynaecologic, dermatologic, and ophthalmologic examinations of the mother were found to be normal, and family history in conjunction with the neurologic, ophthalmologic, and dermatologic findings was unremarkable.

\section{DISCUSSION}

Incontinentia pigmenti is X-linked disorder affecting Skin, Hair, Teeth and Central Nervous System. In most patients, the syndrome occurs sporadically. Germline mutations inherited from the father have been reported in more than $80 \%$ of cases of sporadic disease.[2]

The skin changes are the most characteristic feature in IP which occurs in 4 stages. The first stage which may be present at birth consists of redness/inflammation (Erythema) of the skin, blisters and boils. It may be seen in $90 \%$ of the patients. It may last for few weeks to few months. It may reduce in intensity but later reappear in some cases when there is illness with fever.

The second stage, may overlap with the first, characterised by blisters which develop a raised verrucous (Wart-like) surface and is seen on the extremities. There can be thick crusts or scabs with healing and areas of darkened skin. This stage may last for several months.

The third is the hyperpigmented stage that appears usually between 6-12 months of life. The skin is darkened in a swirled pattern giving a "marble cake" appearance. These hyperpigmented areas does not necessarily coincide with the sites where the stage I and II rashes occurred. The heavy pigmentation tends to fade over time and, in few cases, the pigmented areas thin and widen, leaving streaky diminished colour of the skin (Hypopigmentation).

In the fourth stage, known as the "atrophic" (Scarred) stage, scarring is often present before the hyperpigmentation fades and these are seen in adolescents and adults as pale, hairless patches or streaks. Once the affected individuals reach the late teens and adulthood, the skin changes may fade and may not be visible to the casual observer.

Apart from the clinical findings of skin lesion, the most commonly involved other sites are CNS and visual systems which should be investigated. The CNS is involved in $10-40 \%$ of patients in the form of microcephaly, strokes, seizures, mental retardation, spasticity, and ataxia. Of these, seizure is the most common complication and usually develops within the first few weeks of life. Cerebral microangiopathy and haemorrhagic infarcts cause some of the neurologic morbidity. MRI abnormalities include cortical malformations such as heterotopia, hemimegalencephaly, focal cortical dysplasia, callosal dysgenesis as well as cortical atrophy, and periventricular/white matter lesions. ${ }^{[3]}$ Ocular changes are seen in about one third of patients with IP. Ophthalmologic findings can include retinal pigmentary changes with mottled hypopigmentation, abnormal peripheral retinal vessels with areas of nonperfusion (these two findings are nearly pathognomonic), retinal detachment, cataracts, microphthalmia, optic atrophy, or foveal hypoplasia. Prognosis is good if ocular and CNS abnormalities do not appear by the age of 1 year.[4]

Vesiculopustular disorders of neonates are common; HSV infection, herpes zoster, congenital syphilis, neonatal acne, staphylococcal infections, bullous impetigo, epidermolysis bullosa simplex, Letterer-Siwe disease, transient pustular melanosis, neonatal dermatitis herpetiformis, and IP all have vesiculopustular cutaneous manifestations.[5] In newborns, many examples of erroneous diagnoses of vesiculopustular disorders, made as a result of suspicious findings, can be found in the literature, Herpes simplex being the most common one. ${ }^{[6,7,8]}$ Neonatal HSV infection can show up any time from soon after birth up to and beyond the neonatal period. Seventy-five to $90 \%$ of infants with neonatal HSV are born to women with no history or physical findings suggestive of genital herpes. Exposure to the virus occurs during passage through an infected birth canal, but 5\% infants acquire the infection in utero. Disease can be localised to the skin, eye, and mouth, which without treatment, $70 \%$ of cases progress to a disseminated form involving the CNS or disseminated infection involving multiple organs. On pathology, HSV cause a haemorrhagic and necrotising meningoencephalitis.[9]

\section{CONCLUSION}

Owing to high mortality and morbidity of neonatal HSV infection, it is imperative that we initiate an early acyclovir therapy in neonatal vesicular eruptions, until a detailed clinical and laboratory evaluation can be done. In this case, the cutaneous lesions and CNS manifestations led us to a diagnosis of HSV infection. However, it was the MRI findings and the skin biopsy results that finally clinched the diagnosis of Incontinentia pigmenti. In conclusion, this case report emphasises that IP is a potential masquerader of HSV infection and should be included in the differential diagnosis of cutaneous blistering lesions and CNS involvement in neonates. Lastly, this case emphasises the importance of skin biopsies in vesicular lesions with CNS involvement.

\section{REFERENCES}

1. Landy SJ, Donnai D. Incontinentia Pigmenti (BlockSulzberger syndrome). J Med Genet 1993;30(1):53-9.

2. Berlin AL, Paller AS, Chan LS. Incontinentia Pigmenti: a review and update on the molecular basis of pathophysiology. J Am Acad Dermatol 2002;47(2):169-87.

3. Lee $\mathrm{AG}$, Goldberg $\mathrm{MF}$, Gillard $\mathrm{JH}$, et al. Intracranial assessment of Incontinentia Pigmenti using magnetic resonance imaging, angiography and spectroscopic imaging. Arch Pediatr Adolesc Med 1995;149(5):573-80.

4. Catalano RA. Incontinentia pigmenti. Am J Ophthalmol 1990;110:696-700.

5. Scheuerle AE. Male cases of Incontinentia pigmenti: case report and review. Am J Med Genet 1988;77:210-18.

6. Ciarallo L, Paller AS. Two cases of Incontinentia pigmenti simulating child abuse. Pediatrics 1997;100(4):E6.

7. Detlefs RL, Frieden DJ, Berger TG, et al. Eosinophil fluorescence: a cause of false positive slide tests for herpes simplex virus. Pediatr Dermatol 1987;4(2):129-33.

8. Faloyin M, Levitt J, Bercowitz E, et al. All that is vesicular is not herpes: Incontinentia pigmenti masquerading as herpes simplex virus in a newborn. Pediatrics 2004;114(2):e270-2.

9. Kimberlin D. Herpes simplex virus, meningitis and encephalitis in neonates. Herpes 2004;(11 Suppl 2):65A76A. 